Open Access

\title{
Trends in the geographic distribution of nursing staff before and after the Great East Japan Earthquake: a longitudinal study
}

\author{
Noriko Morioka ${ }^{*}$, Jun Tomio ${ }^{1}$, Toshikazu Seto ${ }^{2}$ and Yasuki Kobayashi ${ }^{1}$
}

\begin{abstract}
Background: Medical care systems in Iwate, Miyagi and Fukushima prefectures were greatly damaged by the Great East Japan Earthquake (GEJE), which struck on 11 March 2011. The shortage of nurses in this area was concerning; however, temporal trends have not been investigated. This study aimed to investigate the trends in the geographic distribution of total nursing staff per population in the secondary medical areas (SMAs) of these prefectures before and after the GEJE. We also aimed to qualify the above trends.
\end{abstract}

Methods: We conducted a longitudinal study at four time points (July 2007, 2010, 2011 and 2013) over 6 years using reports of basic hospitalization charges from all hospitals within Iwate, Miyagi and Fukushima prefectures that experienced severe damage from the GEJE. We calculated the number of total nursing staff per population in the SMAs and compiled descriptive statistics. Changes from 2010 to 2013 were qualified and mapped.

Results: In coastal SMAs, the ratios of total nursing staff per population decreased immediately after the GEJE. In most SMAs in 2013, the ratios increased and exceeded the pre-GEJE level. However, the changes in total nursing staff per population from 2010 to 2013 were negative in Ryouban (-4.0\%), Ishinomaki-Tome-Kesennuma (-1.9\%), Sousou (-47.7\%) and Iwaki (-1.9\%). In Sousou, which is closest to the Fukushima Daiichi Nuclear Power Plant, the changes in total nursing staff per population qualified by job role were $-33.7 \%$ for nurses, $-57.7 \%$ for associate nurses and $-63.2 \%$ for nursing aides.

Conclusions: Our study indicated that the temporal trends in the number of total nursing staff per population due to the GEJE differed between the physically damaged areas and those affected by radiation. We also found the difference in the trend by qualifications: the reduction in total nursing staff per population was larger in Sousou, the area most affected by radiation, than in any other SMAs. Moreover, the number of nursing aides was most affected among the three types of staff. To promote the post-GEJE reconstruction of medical care systems, it might be necessary to develop policies to secure both nurses and nursing aides after nuclear disasters.

Keywords: Great East Japan Earthquake, Nuclear disaster, Geographic distribution, Nurse

\section{Background}

The Great East Japan Earthquake (GEJE) struck on 11 March 2011. The magnitude of the earthquake was 9.0 on the Richter scale, which was the fourth largest worldwide since 1990. Following the earthquake and subsequent tsunamis, there was an explosion at the Fukushima Daiichi Nuclear Power Plant (NPP). By 10 May 2014, 15883 people

\footnotetext{
*Correspondence: nmorioka@m.u-tokyo.ac.jp

'Department of Public Health, Graduate School of Medicine, The University of Tokyo, 7-3-1 Hongo, Bunkyo-ku, Tokyo 113-0033, Japan

Full list of author information is available at the end of the article
}

were dead, 2676 were missing, and 130000 houses were completely destroyed [1]. Health care facilities in the hardest hit areas were also severely damaged [2-4].

These areas had faced a shortage of health care resources for a long time, but the further depletion of health care workers due to the disaster is a growing concern [5]. Health care providers are also more willing to work in natural disaster areas than in radiological or nuclear disaster areas [6]. Particularly in Fukushima, the shortage of nurses is concerning because not only did an earthquake and tsunami cause damage but so too did a nuclear disaster [7]. 
Reconstruction of the health care system after the GEJE is proceeding; however, progress is reported to be slow and uneven across damaged areas [1]. We assumed that there might be a different trend in health care resources before and after the GEJE by the difference in regional damages. However, as far as we know, no study has examined the temporal trends of the nursing workforce such as nurses, associate nurses and nursing aides - in the GEJE-afflicted areas. Nurses comprise most of the health care providers and work on the frontline and contribute to patient outcome [8]; therefore, securing nursing staff is an important issue in health care policy [9]. Although nurse and midwife personnel per thousand population of Japan was 11.489 and the 12th highest in the world [10], the maldistribution and relative shortage of nurses in rural areas in Japan has been of concern [11].

We aimed to describe the temporal trends in the geographic distribution of nursing staff before and after the GEJE, both in total and by job role, per population in the secondary medical areas (SMAs) of Iwate, Miyagi and Fukushima prefectures, which were most affected by the GEJE.

\section{Methods}

\section{Study design}

We conducted a longitudinal study at four time points (July 2007, 2010, 2011 and 2013) before and after the GEJE.

\section{Study setting \\ Study area}

The GEJE-afflicted areas in Iwate, Miyagi and Fukushima prefectures were our study areas (Figure 1). An SMA is a geographical zone for operation of hospital, admission and emergency services. SMA boundaries are defined and revised by each prefecture under the Medical Care Act [12]. Most SMAs are based on a complex of adjacent municipalities, and there are several SMAs in a prefecture. We used the categories of SMAs defined by each prefectural hospital and health planning in 2013 [13-15].

\section{Qualification of total nursing staff in Japan}

In Japan, nurse and associate nurse qualifications are prescribed by the Act on Public Health Nurses, Midwives, and Nurses [16]. Nurses require a national licence, but associate nurses are qualified by prefectural governors, and both licensures are effective anywhere in Japan. Nurses have to study for at least 3 years at nursing school or university, whereas associate nurses have to study for only 2 years. Although the practical training and educational achievements differ between the two types of nurses, associate nurses are permitted to provide nursing services under the direction of a physician, dentist or nurse. Nursing aides are not required to be qualified and assist nurses in providing personal care of patients under nurses' supervision and housekeeping work, such as washing laundry, cleaning up and clerical tasks in hospitals [17].

\section{Variables and data sources \\ Damage caused by the GEJE}

Each prefectural government identified the number of deaths and collapsed houses caused by the GEJE as the indicators of damage [18-20]. We depicted the mortality in each SMA, which was calculated by the number of deaths per 10000 population in 2010 [21-23], as an indicator of the physical damage caused by the GEJE (Figure 1). As Garber et al. [24] identified the heavily affected areas by disaster by flooded or having extensive or catastrophic damage, we referred to the high mortality area as the physically damaged area. According to the UNISDR, loss of life, or mortality, is one of the key indicators of disaster impacts in general [25]. As for the effect of the NPP accident, we pointed the atmospheric radiation dose rate $(\mu \mathrm{Sv} / \mathrm{h})$ as on 19 November 2013, which was the latest available data during the study period (Figure 1), using the categories of the Japanese government. The Japanese government set the cut-off points for the atmospheric radiation dose rate as follows: (1) $0.23 \mu \mathrm{Sv} / \mathrm{h}$, which is equivalent to $1 \mathrm{mSv} /$ year under the assumption of a life pattern of $16 \mathrm{~h}$ indoor (wooden construction) and 8-h outdoor activity per day, and for higher rates, it is necessary for national governments to carry out measures for decontamination; (2) $2.5 \mu \mathrm{Sv} / \mathrm{h}$, which is equivalent to $5 \mathrm{mSv} /$ year under the assumption of $40 \mathrm{~h} /$ week working outdoors, and for higher rates, it is necessary for the government to measure workers' exposure dose; and (3) $3.8 \mu \mathrm{Sv} / \mathrm{h}$, which is equivalent to $20 \mathrm{mSv} /$ year under the assumption of a life pattern of $16 \mathrm{~h}$ indoor (wooden construction) and 8-h outdoor activity per day, and the government designates the area as an evaluation area [26,27]. We obtained the atmospheric radiation dose rate from establishment of the Extension Site of Distribution Map of Radiation Dose [28].

\section{Number of total nursing staff}

The numbers of nurses, associate nurses and nursing aides were obtained from full-time equivalent (FTE) hospital employees. The number of FTE hospital employees for part-time personnel was calculated by dividing the full-time worker's working time by actual working time during June. Nurses included midwives and public health nurses who were employed by hospitals. The number of total nursing staff was the sum of the number of nurses, associate nurses and nursing aides.

The number of total nursing staff at each hospital in 2007, 2010, 2011 and 2013 was obtained from reports about basic hospitalization charges [29]. We collected 


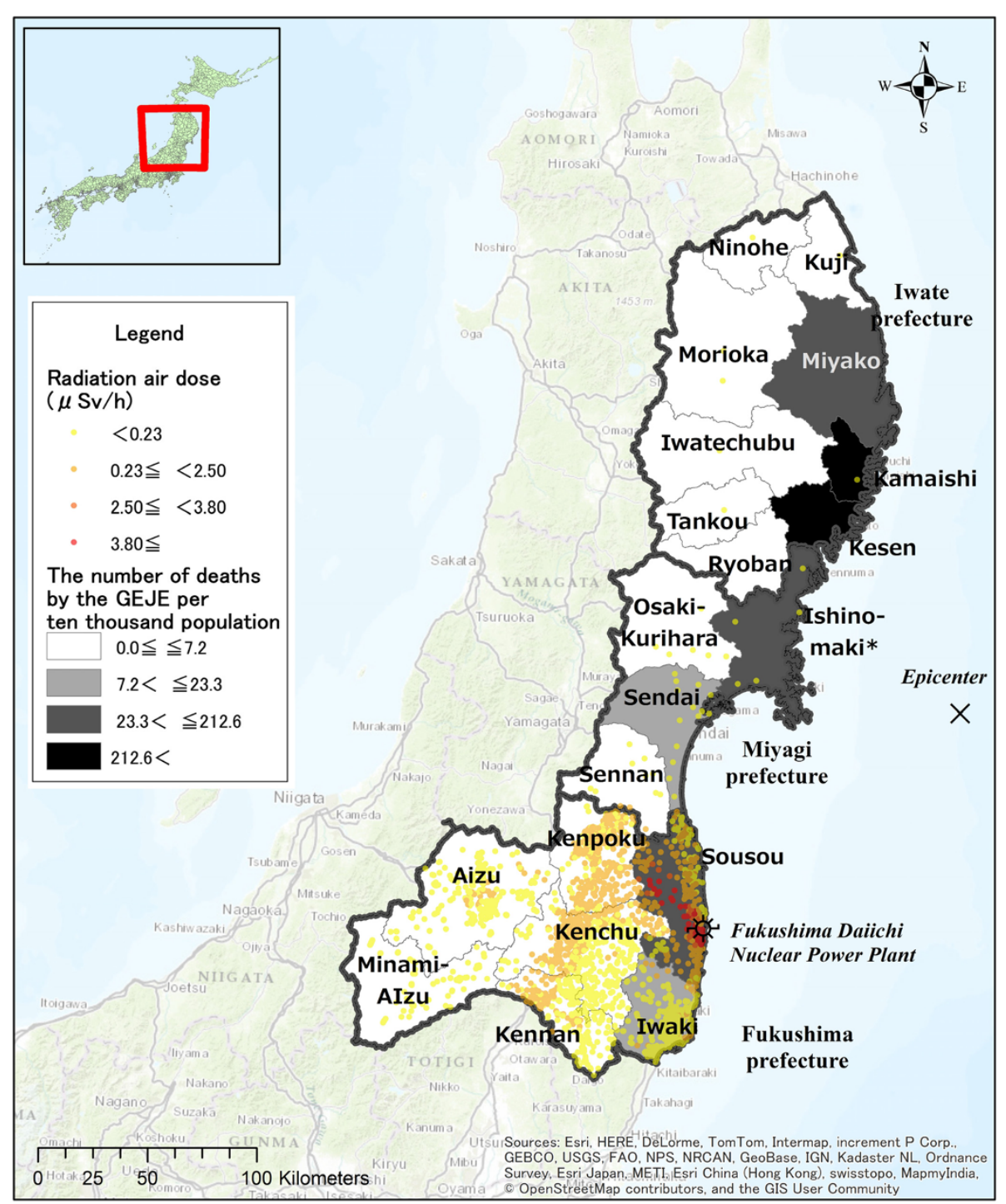

Figure 1 Damage caused by the Great East Japan Earthquake (GEJE) in Iwate, Miyagi and Fukushima prefectures.

these reports from all hospitals in Iwate, Miyagi and Fukushima prefectures by requesting disclosure of administrative documents from the Tohoku Regional Bureau of Health and Welfare on 15 October 2013. All hospitals have to submit their routine reports for the reimbursement of public health insurance based on actual data during June to each Regional Bureau of Health and Welfare office in July every year. These reports included the following information: hospital address (municipality); ownership; type of wards (for example, general, long-term care and psychiatric); number of beds; numbers of nurses, associate nurses and nursing aides; and daily ratio of total nursing staff per inpatients. Nationwide data for reference were collected by hospital reports, which are submitted on 1 October annually [30].
The population of the municipalities in each prefecture was obtained from the estimated population on 1 October annually [21-23]. The nationwide population for reference was acquired from the estimated population on 1 October annually [31].

\section{Geographical data}

Data on the boundaries of municipalities were obtained from the National Land Numerical Information Service provided by the Ministry of Land, Infrastructure, Transport, and Tourism [32]. We created the SMA boundaries using the above data. In this study, we used ArcGIS version 10.1 (ESRI Inc., Redlands, CA, USA) for the geographical analysis. 


\section{Statistical analysis}

Descriptive statistics about total nursing staff and population were collected by SMAs. We also calculated the ratio of total nursing staff per 1000 in the total population and as separated by qualifications in all SMAs from July 2010 to July 2013, to show the changes in the ratio before and after the GEJE. All analyses were performed with Stata version 13.1 (Stata Corp., College Station, TX, USA).

\section{Results}

Table 1 shows the temporal trends of the total number of population, hospitals and total nursing staff in Japan. The ratio of total nursing staff per population shows a steady increase from 2007 to 2013.

\section{Location and damage from the GEJE in SMAs}

There are 20 SMAs (9 in Iwate, 4 in Miyagi and 7 in Fukushima) within the study areas. In coastal SMAs, the mortality caused by the GEJE was higher than those in inland SMAs (Figure 1).

\section{SMA characteristics}

Table 2 shows the temporal trends of the population, hospitals and total nursing staff in the SMAs in Iwate, Miyagi and Fukushima prefectures. The total number of hospitals in the three prefectures as of July 2007, 2010, 2011 and 2013 were 389, 380, 348 and 359, respectively. The maximum population in 2013 was 1.5 million in Sendai, Miyagi, and the minimum was 28282 in Minamiaizu, Fukushima. In all SMAs, excluding Sendai and Ryouban, the population tended to decrease from 2007 to 2013. In coastal SMAs (Kamaishi, Kesen, IshinomakiTome-Kesennuma (Ishinomaki), Sennan, Sousou and Iwaki), the number of hospitals and total nursing staff tended to decrease from 2010 to 2011.

Trends in the ratio of total nursing staff per population Table 3 shows the temporal trends of the ratio of total nursing staff and by qualification per population in

Table 1 Trend characteristics before and after the Great East Japan Earthquake (GEJE) in Japan

\begin{tabular}{lllllll}
\hline Variables & \multicolumn{2}{l}{ Before GEJE } & & \multicolumn{2}{l}{ After GEJE } \\
\cline { 2 - 3 } & $\mathbf{2 0 0 7}$ & $\mathbf{2 0 1 0}$ & & $\mathbf{2 0 1 1}$ & $\mathbf{2 0 1 3}$ \\
\hline Population (thousand persons) & 127771 & 128057 & & 127799 & 127298 \\
Number of hospitals & 8876 & 8685 & & 8620 & 8553 \\
Nursing staffs per thousand & 7.87 & 8.31 & & 8.45 & 8.77 \\
Nurses per thousand & 4.99 & 5.52 & & 5.71 & 6.08 \\
Associate nurses per thousand & 1.38 & 1.26 & & 1.20 & 1.12 \\
Nursing aides per thousand & 1.49 & 1.53 & & 1.54 & 1.57 \\
\hline
\end{tabular}

Note: Population at 1 October in each year.

Number of hospitals and nursing staff on 1 October in each year.
Iwate, Miyagi and Fukushima prefectures. The maximum ratio of total nursing staff per 1000 population in 2013 was 11.38 in Kamaishi, and the minimum was 3.32 in Minamiaizu. In most SMAs, the ratio of total nursing staff per population tended to increase from 2007 to 2013. However, in Kuji, Kamaishi, Ryouban, Ishinomaki, Sennan, Sousou and Iwaki, the ratio of total nursing staff per population decreased from 2010 to 2011.

According to qualification, the ratio of nurses per population tended to increase from 2007 to 2013 in 14 SMAs, excluding Kuji, Kamaishi, Ryouban, Ishinomaki, Sousou and Iwaki. In these six SMAs, the ratio of nurses tended to increase from 2007 to 2010, decrease from 2010 to 2011 and then increase again after 2011. The ratio of associate nurses per population peaked in 2007 and has decreased since then in most SMAs. The ratio of nursing aides per population tended to increase from 2007 to 2013 in 14 SMAs, excluding Kuji, Kamaishi, Kesen, Ishinomaki, Sousou and Iwaki. In these six SMAs, the ratio of nursing aides decreased from 2010 to 2011 and increased again after 2011. In Sousou, the reductions in the ratio for all qualifications from 2010 to 2011 were the largest compared with other SMAs. The percentages of nurses, associate nurses and nursing aides were $-51.2 \%,-79.6 \%$ and $-78.7 \%$, respectively.

\section{Changes before and after the GEJE}

Changes in the ratio of total nursing staff and by qualification per population from 2010 to 2013 are shown in Table 3, Figures 2 and 3 . The percent changes in total nursing staff per population were negative in four SMAs: Ryouban $(-4.0 \%)$, Ishinomaki $(-1.9 \%)$, Sousou $(-47.7 \%)$ and Iwaki $(-1.9 \%)$. According to qualifications, the percent changes in nurses per population were negative in three SMAs: Tankou $(-0.8 \%)$, Ryouban $(-4.0 \%)$ and Sousou $(-33.7 \%)$. Those of associate nurses were negative in all SMAs excluding Tankou (3.4\%) and Minamiaizu (48.0\%), and the largest decrease was found in Sousou (-57.7\%). A large decrease in the ratio of nursing aides was found in Sousou (-63.2\%), while the ratios of nursing aides increased in all the other SMAs. For all qualifications, the ratio of total nursing staff per population in Sousou decreased the most.

\section{Discussion}

Our study indicated that the trend in the ratio of total nursing staff per population after the GEJE was different between the physically damaged areas and those affected by radiation. In coastal SMAs, which were greatly damaged by tsunamis, the ratio of total nursing staff per population greatly decreased immediately after the GEJE, as indicated previously [2-5]. In most SMAs, because the reconstruction of hospitals was progressing after the GEJE, the ratio of total nursing staff per population increased and exceeded the pre-GEJE level for 2 years. In 
Table 2 Secondary Medical Area (SMA) characteristics of Iwate, Miyagi, and Fukushima prefectures

\begin{tabular}{|c|c|c|c|c|c|c|}
\hline \multirow[t]{2}{*}{ Prefecture } & \multirow{2}{*}{$\begin{array}{l}\text { Secondary } \\
\text { Medical Area (SMA) }\end{array}$} & \multirow[t]{2}{*}{ Variables } & \multicolumn{2}{|l|}{ Before GEJE } & \multicolumn{2}{|l|}{ After GEJE } \\
\hline & & & 2007 (changes in \% from 2010) $^{b}$ & 2010 (reference) & 2011 (changes in \% from 2010) ${ }^{\mathrm{b}, \mathrm{c}}$ & 2013 (changes in \% from 2010) \\
\hline \multirow[t]{27}{*}{ Iwate Prefecture } & \multirow[t]{3}{*}{ Kuji } & Population & $64843(3.7)$ & 62505 & $61535(-1.6)$ & $60142(-3.8)$ \\
\hline & & Number of hospitals & $4(0.0)$ & 4 & $4(0.0)$ & $4(0.0)$ \\
\hline & & Number of nursing staff & $408(-5.3)$ & 431 & $413(-4.2)$ & $418(-3.0)$ \\
\hline & \multirow[t]{3}{*}{ Ninohe } & Population & $63169(4.2)$ & 60605 & $59708(-2.5)$ & $57913(-4.4)$ \\
\hline & & Number of hospitals & $3(0.0)$ & 3 & $3(0.0)$ & $3(0.0)$ \\
\hline & & Number of nursing staff & $420(-6.0)$ & 447 & $458(2.5)$ & $454(1.6)$ \\
\hline & \multirow[t]{3}{*}{ Miyako } & Population & $93529(0.9)$ & 92694 & $89176(-3.8)$ & $86302(-6.9)$ \\
\hline & & Number of hospitals & $7(16.7)$ & 6 & $5(-16.7)$ & $5(-16.7)$ \\
\hline & & Number of nursing staff & $706(-6.5)$ & 755 & $756(0.1)$ & $708(-6.2)$ \\
\hline & \multirow[t]{3}{*}{ Morioka } & Population & $486107(0.9)$ & 481699 & $482096(0.1)$ & $481217(-0.1)$ \\
\hline & & Number of hospitals & $42(2.4)$ & 41 & $39(-4.9)$ & $39(-4.9)$ \\
\hline & & Number of nursing staff & $4735(-5.2)$ & 4994 & $5024(0.6)$ & $5451(9.2)$ \\
\hline & \multirow[t]{3}{*}{ Kamaishi } & Population & $57496(4.8)$ & 54850 & $49952(-8.9)$ & $48153(-12.2)$ \\
\hline & & Number of hospitals & $6(0.0)$ & 6 & $5(-16.7)$ & $5(-16.7)$ \\
\hline & & Number of nursing staff & $560(-1.2)$ & 567 & $505(-10.9)$ & $548(-3.4)$ \\
\hline & \multirow[t]{3}{*}{ Iwatechubu } & Population & $236254(2.5)$ & 230509 & $229713(-0.3)$ & $227303(-1.4)$ \\
\hline & & Number of hospitals & $14(7.7)$ & 13 & $13(0.0)$ & $13(0.0)$ \\
\hline & & Number of nursing staff & $1331(-5.9)$ & 1415 & $1490(5.3)$ & $1448(2.3)$ \\
\hline & \multirow[t]{3}{*}{ Kesen } & Population & 72755 (3.6) & 70227 & $65552(-6.7)$ & $64169(-8.6)$ \\
\hline & & Number of hospitals & $4(33.3)$ & 3 & $2(-33.3)$ & $3(0.0)$ \\
\hline & & Number of nursing staff & $388(-5.6)$ & 411 & $388(-5.6)$ & $420(2.2)$ \\
\hline & \multirow[t]{3}{*}{ Tankou } & Population & $144795(2.6)$ & 141071 & $140066(-0.7)$ & $137659(-2.4)$ \\
\hline & & Number of hospitals & $10(0.0)$ & 10 & $10(0.0)$ & $10(0.0)$ \\
\hline & & Number of nursing staff & $973(0.2)$ & 971 & $1013(4.3)$ & $997(2.7)$ \\
\hline & \multirow[t]{3}{*}{ Ryouban } & Population & $131991(4.0)$ & 126923 & $134958(6.3)$ & $131595(3.7)$ \\
\hline & & Number of hospitals & $10(0.0)$ & 10 & $9(-10.0)$ & $9(-10.0)$ \\
\hline & & Number of nursing staff & $1017(0.5)$ & 1012 & $1047(3.5)$ & $1007(-0.5)$ \\
\hline \multirow[t]{5}{*}{ Miyagi Prefecture } & \multirow[t]{3}{*}{ Ishinomaki } & Population & $398991(2.7)$ & 388667 & $367725(-5.4)$ & $358816(-7.7)$ \\
\hline & & Number of hospitals & $25(0.0)$ & 25 & $16(-36.0)$ & $20(-20.0)$ \\
\hline & & Number of nursing staff & $2465(-3.8)$ & 2563 & $2065(-19.4)$ & $2321(-9.4)$ \\
\hline & \multirow[t]{2}{*}{ Osaki-Kurihara } & Population & $293307(2.7)$ & 285721 & $284387(-0.5)$ & $279962(-2.0)$ \\
\hline & & Number of hospitals & $27(0.0)$ & 27 & $27(0.0)$ & $26(-3.7)$ \\
\hline
\end{tabular}


Table 2 Secondary Medical Area (SMA) characteristics of Iwate, Miyagi, and Fukushima prefectures (Continued)

\begin{tabular}{|c|c|c|c|c|c|c|}
\hline & & Number of nursing staff & $1935(0.5)$ & 1926 & $2000(3.8)$ & $2057(6.8)$ \\
\hline & Sendai & Population & $1468320(-1.5)$ & 1490098 & $1488608(-0.1)$ & 1509985 (1.3) \\
\hline & & Number of hospitals & $77(-3.8)$ & 80 & $78(-2.5)$ & $81(1.3)$ \\
\hline & & Number of nursing staff & $10135(-9.9)$ & 11243 & $11407(1.5)$ & $12058(7.2)$ \\
\hline & Sennan & Population & $188381(2.6)$ & 183679 & $182504(-0.6)$ & $179380(-2.3)$ \\
\hline & & Number of hospitals & $13(0.0)$ & 13 & $12(-7.7)$ & $13(0.0)$ \\
\hline & & Number of nursing staff & $1080(0.7)$ & 1072 & $1049(-2.1)$ & 1196 (11.6) \\
\hline \multirow[t]{21}{*}{ Fukushima Prefecture } & Sousou & Population & $198390(1.2)$ & 195950 & $185575(-5.3)$ & $180194(-8.0)$ \\
\hline & & Number of hospitals & $17(6.3)$ & 16 & $6(-62.5)$ & $9(-43.8)$ \\
\hline & & Number of nursing staff & $1485(2.4)$ & 1450 & $467(-67.8)$ & $698(-51.9)$ \\
\hline & Kenpoku & Population & $505531(1.7)$ & 497059 & $489068(-1.6)$ & $478602(-3.7)$ \\
\hline & & Number of hospitals & $34(6.3)$ & 32 & $32(0.0)$ & $32(0.0)$ \\
\hline & & Number of nursing staff & $3587(-10.7)$ & 4018 & $4054(0.9)$ & $4017(0.0)$ \\
\hline & Aizu & Population & $271634(3.7)$ & 262051 & $259617(-0.9)$ & $253301(-3.3)$ \\
\hline & & Number of hospitals & $19(0.0)$ & 19 & $19(0.0)$ & $18(-5.3)$ \\
\hline & & Number of nursing staff & $2725(-3.8)$ & 2833 & $2953(4.2)$ & $2812(-0.7)$ \\
\hline & Kenchuu & Population & $558249(1.2)$ & 551745 & $542444(-1.7)$ & $533286(-3.3)$ \\
\hline & & Number of hospitals & $34(3.0)$ & 33 & $31(-6.1)$ & $33(0.0)$ \\
\hline & & Number of nursing staff & $4571(-1.9)$ & 4660 & $4646(-0.3)$ & $4864(4.4)$ \\
\hline & Iwaki & Population & $350258(2.3)$ & 342249 & $334280(-2.3)$ & $327856(-4.2)$ \\
\hline & & Number of hospitals & $29(0.0)$ & 29 & $26(-10.3)$ & $26(-10.3)$ \\
\hline & & Number of nursing staff & $2973(-4.5)$ & 3112 & $2926(-6.0)$ & $2923(-6.1)$ \\
\hline & Kennan & Population & $152517(1.6)$ & 150117 & $148595(-1.0)$ & $146059(-2.7)$ \\
\hline & & Number of hospitals & $13(44.4)$ & 9 & $10(11.1)$ & $9(0.0)$ \\
\hline & & Number of nursing staff & $1097(11.0)$ & 988 & $1111(12.4)$ & $1085(9.8)$ \\
\hline & Minamiaizu & Population & $31773(6.3)$ & 29893 & $29416(-1.6)$ & $28282(-5.4)$ \\
\hline & & Number of hospitals & $1(0.0)$ & 1 & $1(0.0)$ & $1(0.0)$ \\
\hline & & Number of nursing staff & $88(-3.3)$ & 91 & $101(11.0)$ & $94(3.3)$ \\
\hline \multirow[t]{3}{*}{ Total } & & Population & $5768290(1.2)$ & 5698312 & $5624975(-1.3)$ & $5570176(-2.2)$ \\
\hline & & Number of hospitals & $389(2.4)$ & 380 & $348(-8.4)$ & $359(-5.5)$ \\
\hline & & Number of nursing staff & $42679(-5.1)$ & 44959 & $43873(-2.4)$ & $45576(1.4)$ \\
\hline
\end{tabular}

Ishinomaki-Tome-Kesennuma.

${ }^{\mathrm{b}}$ Changes in \% in reference to 2010.

'Figures after the Great East Japan Earthquake. Negative change is shown in italic text. 
Table $\mathbf{3}$ Trends in nursing staff per thousand population by qualifications in Iwate, Miyagi and Fukushima prefectures

\begin{tabular}{|c|c|c|c|c|c|c|}
\hline \multirow[t]{2}{*}{ Prefecture } & \multirow[t]{2}{*}{ SMA } & \multirow[t]{2}{*}{ Variables } & \multicolumn{2}{|l|}{ Before GEJE } & \multicolumn{2}{|l|}{ After GEJE } \\
\hline & & & 2007 (changes in \% from 2010) $^{b}$ & 2010 (reference) & 2011 (changes in \% from 2010) & 2013 (changes in \% from 2010) ) $^{\mathrm{b}, \mathrm{c}}$ \\
\hline \multirow[t]{32}{*}{ Iwate Prefecture } & \multirow[t]{4}{*}{ Kuji } & Nursing staff & $6.29(-8.7)$ & 6.90 & $6.71(-2.7)$ & $6.95(0.8)$ \\
\hline & & Nurses & $4.50(-7.4)$ & 4.86 & $4.81(-1.1)$ & $4.97(2.2)$ \\
\hline & & Associate nurses & $0.94(8.9)$ & 0.86 & $0.86(-0.3)$ & $0.71(-17.2)$ \\
\hline & & Nursing aides & $0.85(-27.4)$ & 1.17 & $1.04(-10.9)$ & $1.26(8.2)$ \\
\hline & \multirow[t]{4}{*}{ Ninohe } & Nursing staff & $6.65(-9.9)$ & 7.38 & $7.67(4.0)$ & $7.84(6.3)$ \\
\hline & & Nurses & $5.13(-11.4)$ & 5.79 & $5.88(1.5)$ & $6.04(4.4)$ \\
\hline & & Associate nurses & $0.82(24.7)$ & 0.66 & $0.60(-8.6)$ & $0.54(-18.9)$ \\
\hline & & Nursing aides & $0.70(-24.6)$ & 0.92 & $1.19(28.7)$ & $1.26(36.4)$ \\
\hline & \multirow[t]{4}{*}{ Miyako } & Nursing staff & $7.55(-7.3)$ & 8.15 & $8.48(4.1)$ & $8.20(0.7)$ \\
\hline & & Nurses & $4.83(-6.9)$ & 5.19 & $5.29(2.0)$ & $5.21(0.5)$ \\
\hline & & Associate nurses & $1.32(24.4)$ & 1.06 & $1.09(2.9)$ & $1.05(-0.3)$ \\
\hline & & Nursing aides & $1.40(-26.2)$ & 1.90 & $2.10(10.4)$ & $1.94(1.9)$ \\
\hline & \multirow[t]{4}{*}{ Morioka } & Nursing staff & $9.74(-6.0)$ & 10.37 & $10.42(0.5)$ & $11.33(9.3)$ \\
\hline & & Nurses & $7.13(-7.9)$ & 7.75 & $7.84(1.2)$ & $8.47(9.4)$ \\
\hline & & Associate nurses & $1.13(9.5)$ & 1.03 & $1.00(-3.5)$ & $0.96(-6.7)$ \\
\hline & & Nursing aides & $1.48(-6.9)$ & 1.59 & $1.58(-0.3)$ & $1.89(19.0)$ \\
\hline & \multirow[t]{4}{*}{ Kamaishi } & Nursing staff & $9.74(-5.8)$ & 10.34 & $10.11(-2.2)$ & 11.38 (10.1) \\
\hline & & Nurses & $7.08(-4.4)$ & 7.40 & $7.37(-0.5)$ & 8.16 (10.3) \\
\hline & & Associate nurses & $1.39(-2.2)$ & 1.42 & $1.34(-5.7)$ & $1.25(-12.4)$ \\
\hline & & Nursing aides & $1.27(-16.1)$ & 1.51 & $1.40(-7.4)$ & $1.97(30.4)$ \\
\hline & \multirow[t]{4}{*}{ Iwatechubu } & Nursing staff & $5.63(-8.2)$ & 6.14 & $6.49(5.7)$ & 6.37 (3.8) \\
\hline & & Nurses & $4.43(-5.5)$ & 4.69 & $4.90(4.5)$ & $4.73(0.9)$ \\
\hline & & Associate nurses & $0.63(13.5)$ & 0.56 & $0.57(2.7)$ & $0.50(-11.2)$ \\
\hline & & Nursing aides & $0.57(-36.2)$ & 0.89 & 1.01 (13.6) & $1.14(28.1)$ \\
\hline & \multirow[t]{4}{*}{ Kesen } & Nursing staff & $5.33(-8.9)$ & 5.85 & $5.92(1.1)$ & $6.55(11.8)$ \\
\hline & & Nurses & $4.40(3.0)$ & 4.27 & $4.36(2.1)$ & $4.96(16.0)$ \\
\hline & & Associate nurses & $0.56(-20.8)$ & 0.71 & $0.70(-1.4)$ & $0.56(-21.2)$ \\
\hline & & Nursing aides & $0.37(-57.3)$ & 0.87 & $0.85(-1.6)$ & $1.03(18.4)$ \\
\hline & \multirow[t]{4}{*}{ Tankou } & Nursing staff & $6.72(-2.4)$ & 6.88 & $7.23(5.1)$ & $7.24(5.2)$ \\
\hline & & Nurses & $4.68(-4.1)$ & 4.88 & $5.20(6.6)$ & $4.84(-0.8)$ \\
\hline & & Associate nurses & $0.90(12.0)$ & 0.81 & $0.81(-0.2)$ & $0.84(3.4)$ \\
\hline & & Nursing aides & $1.14(-4.0)$ & 1.20 & $1.23(2.5)$ & $1.57(31.0)$ \\
\hline
\end{tabular}


Table 3 Trends in nursing staff per thousand population by qualifications in Iwate, Miyagi and Fukushima prefectures (Continued)

\begin{tabular}{|c|c|c|c|c|c|c|}
\hline & Ryouban & Nursing staff & $7.71(-3.4)$ & 7.97 & $7.76(-2.7)$ & $7.65(-4.0)$ \\
\hline & & Nurses & $5.95(-4.9)$ & 6.26 & $5.98(-4.4)$ & $6.00(-4.0)$ \\
\hline & & Associate nurses & $0.94(21.7)$ & 0.77 & $0.76(-1.2)$ & $0.62(-20.3)$ \\
\hline & & Nursing aides & $0.82(-13.5)$ & 0.95 & $1.02(7.4)$ & $1.03(9.3)$ \\
\hline \multirow[t]{16}{*}{ Miyagi Prefecture } & Ishinomakia & Nursing staff & $6.18(-6.3)$ & 6.59 & $5.62(-14.8)$ & $6.47(-1.9)$ \\
\hline & & Nurses & $3.90(-8.5)$ & 4.26 & $3.79(-11.0)$ & $4.36(2.2)$ \\
\hline & & Associate nurses & $1.28(4.6)$ & 1.23 & $0.94(-23.1)$ & $0.94(-23.2)$ \\
\hline & & Nursing aides & $0.99(-10.1)$ & 1.10 & $0.88(-20.4)$ & $1.17(5.8)$ \\
\hline & Osaki-Kurihara & Nursing staff & $6.60(-2.1)$ & 6.74 & $7.03(4.3)$ & 7.35 (9.0) \\
\hline & & Nurses & $3.68(-9.0)$ & 4.04 & $4.20(4.0)$ & $4.57(13.1)$ \\
\hline & & Associate nurses & 1.69 (21.6) & 1.39 & $1.44(3.5)$ & $1.35(-3.3)$ \\
\hline & & Nursing aides & $1.23(-6.2)$ & 1.31 & $1.39(6.1)$ & $1.43(9.4)$ \\
\hline & Sendai & Nursing staff & $6.90(-8.5)$ & 7.55 & $7.66(1.6)$ & 7.99 (5.8) \\
\hline & & Nurses & $5.12(-10.3)$ & 5.70 & $5.82(2.1)$ & $6.15(7.8)$ \\
\hline & & Associate nurses & $0.89(9.8)$ & 0.81 & $0.73(-10.2)$ & $0.65(-19.8)$ \\
\hline & & Nursing aides & $0.90(-13.3)$ & 1.03 & $1.12(7.9)$ & $1.19(15.0)$ \\
\hline & Sennan & Nursing staff & $5.73(-1.8)$ & 5.84 & $5.75(-1.5)$ & $6.67(14.2)$ \\
\hline & & Nurses & $2.84(-7.2)$ & 3.06 & $3.15(2.8)$ & $3.70(20.8)$ \\
\hline & & Associate nurses & 1.57 (15.9) & 1.36 & $1.14(-15.9)$ & $1.18(-13.2)$ \\
\hline & & Nursing aides & $1.32(-7.0)$ & 1.42 & $1.46(3.0)$ & $1.80(26.3)$ \\
\hline \multirow[t]{13}{*}{ Fukushima Prefecture } & Sousou & Nursing staff & $7.49(1.2)$ & 7.40 & $2.52(-66.0)$ & $3.87(-47.7)$ \\
\hline & & Nurses & $3.28(-6.0)$ & 3.49 & $1.70(-51.2)$ & $2.31(-33.7)$ \\
\hline & & Associate nurses & $2.56(17.0)$ & 2.19 & $0.45(-79.6)$ & $0.93(-57.7)$ \\
\hline & & Nursing aides & $1.64(-4.5)$ & 1.72 & $0.37(-78.7)$ & $0.63(-63.2)$ \\
\hline & Kenpoku & Nursing staff & $7.10(-12.2)$ & 8.08 & $8.29(2.5)$ & $8.39(3.8)$ \\
\hline & & Nurses & $4.37(-16.1)$ & 5.21 & $5.45(4.6)$ & $5.67(9.0)$ \\
\hline & & Associate nurses & $1.59(9.5)$ & 1.46 & $1.36(-6.4)$ & $1.23(-15.8)$ \\
\hline & & Nursing aides & $1.13(-20.4)$ & 1.42 & $1.48(4.2)$ & $1.49(5.2)$ \\
\hline & Aizu & Nursing staff & $10.03(-7.2)$ & 10.81 & $11.37(5.2)$ & $11.10(2.7)$ \\
\hline & & Nurses & $6.27(-6.9)$ & 6.73 & $7.20(6.9)$ & $7.18(6.7)$ \\
\hline & & Associate nurses & $2.21(-4.8)$ & 2.32 & $2.33(0.4)$ & $2.12(-8.9)$ \\
\hline & & Nursing aides & $1.55(-11.7)$ & 1.76 & $1.85(5.1)$ & $1.80(2.8)$ \\
\hline & Kenchuu & Nursing staff & $8.19(-3.1)$ & 8.45 & $8.56(1.4)$ & $9.12(8.0)$ \\
\hline
\end{tabular}


Table 3 Trends in nursing staff per thousand population by qualifications in Iwate, Miyagi and Fukushima prefectures (Continued)

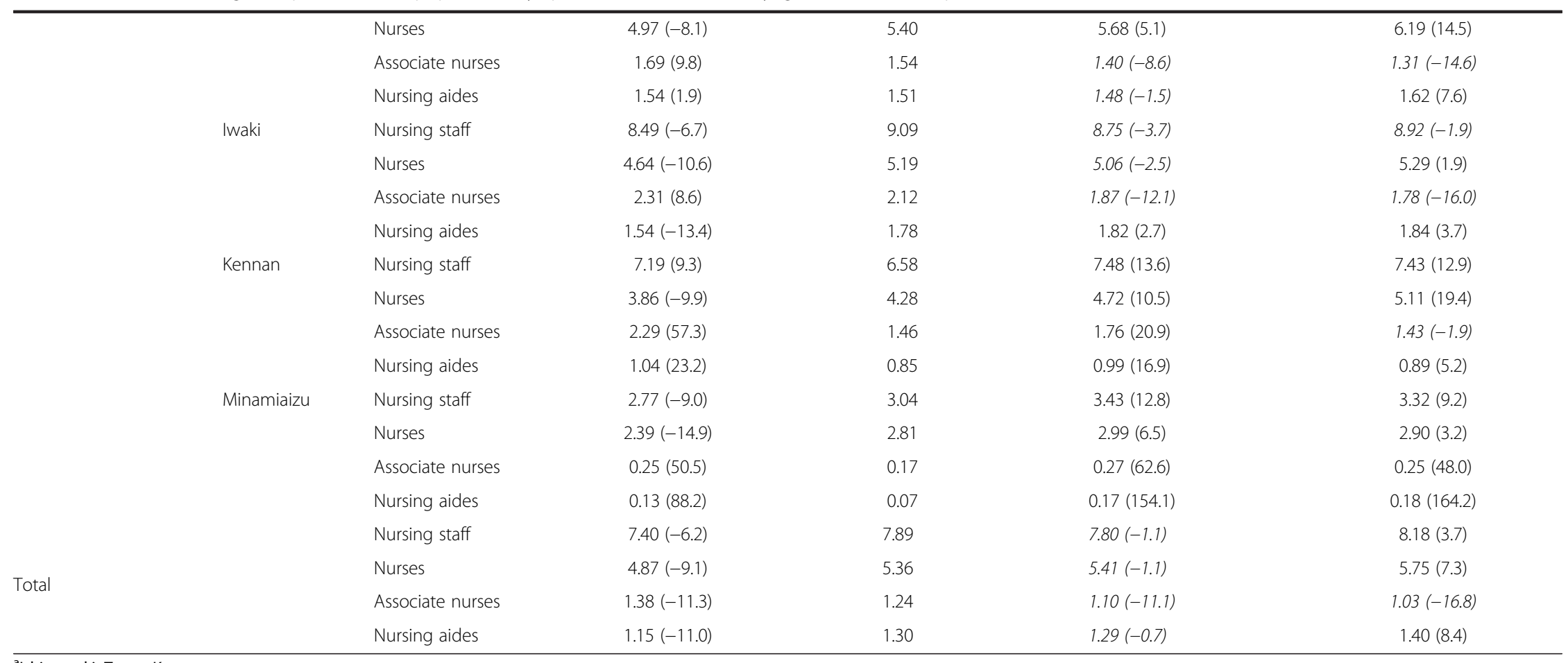

alshinomaki-Tome-Kesennuma.
${ }^{\mathrm{b}}$ Changes in \% in reference to 2010 .

${ }^{C}$ Figures after the Great East Japan Earthquake. Negative change is shown in italic text. 


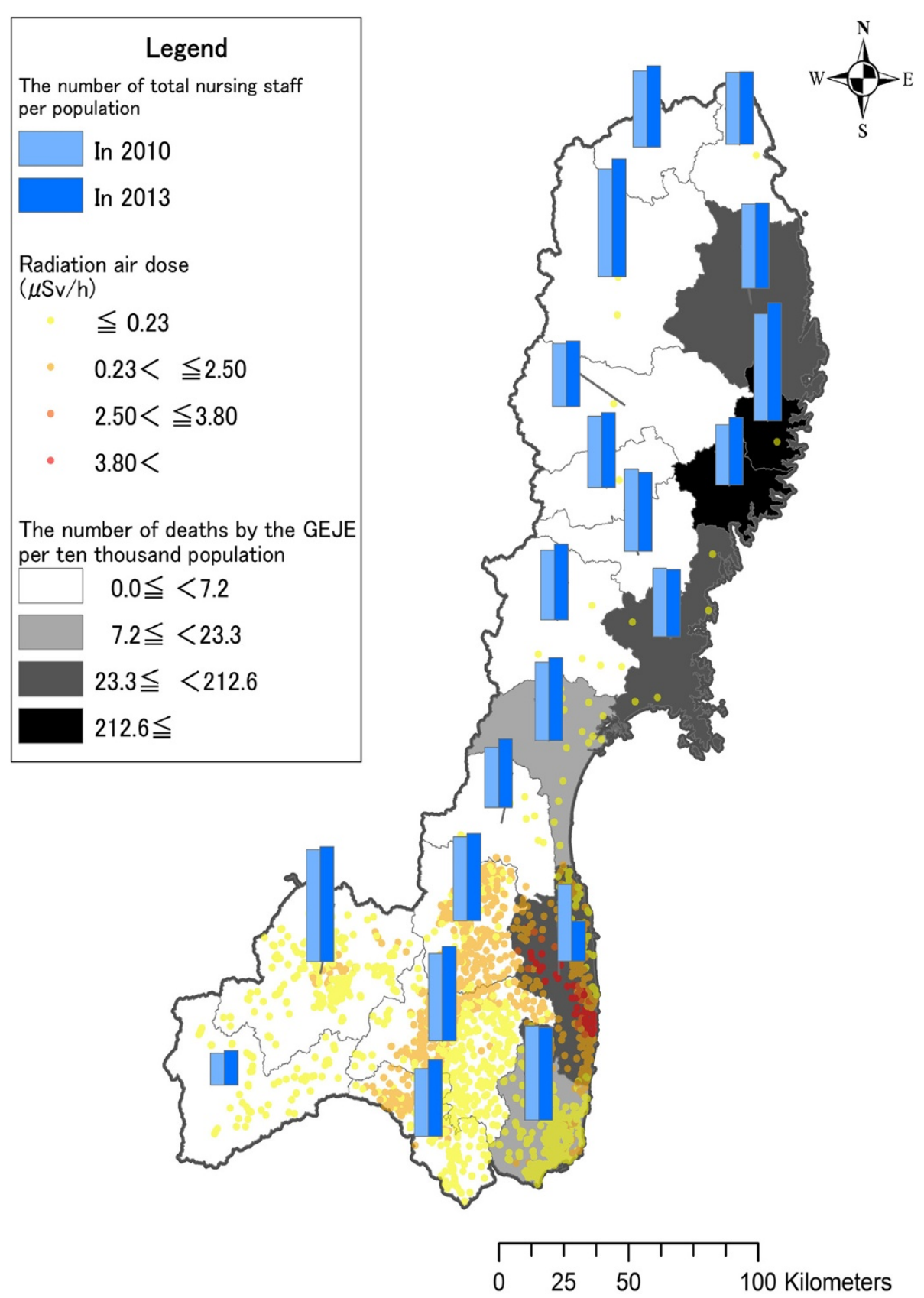

Figure 2 Number of total nursing staff per population in 2010 and in 2013.

four SMAs (Ryouban, Ishinomaki, Sousou and Iwaki), the ratio of total nursing staff per population had not yet recovered to the pre-GEJE level. In Ryouban, Ishinomaki and Iwaki, the ratio of total nursing staff per population achieved almost $96 \%$ and over before the GEJE. In the inland area of Ryouban, the decrease in total nursing staff per population was caused by the post-GEJE increase in population. In Ishinomaki and Iwaki, which were one of the greatest damaged by the tsunami, the decrease in total nursing staff per population was explained by the decrease in associate nurses.

In Sousou, the SMA where the NPP is located and which was also severely damaged by the earthquake and tsunamis, the total nursing staff per population in 2013 was only half of that in 2010. The number of physicians per 100000 population also decreased by $34.4 \%$ (from 120.4 on 31 December 2010 to 79.0 on 31 December 2012) in Sousou [33], which was almost the same as the reduction of nurses 

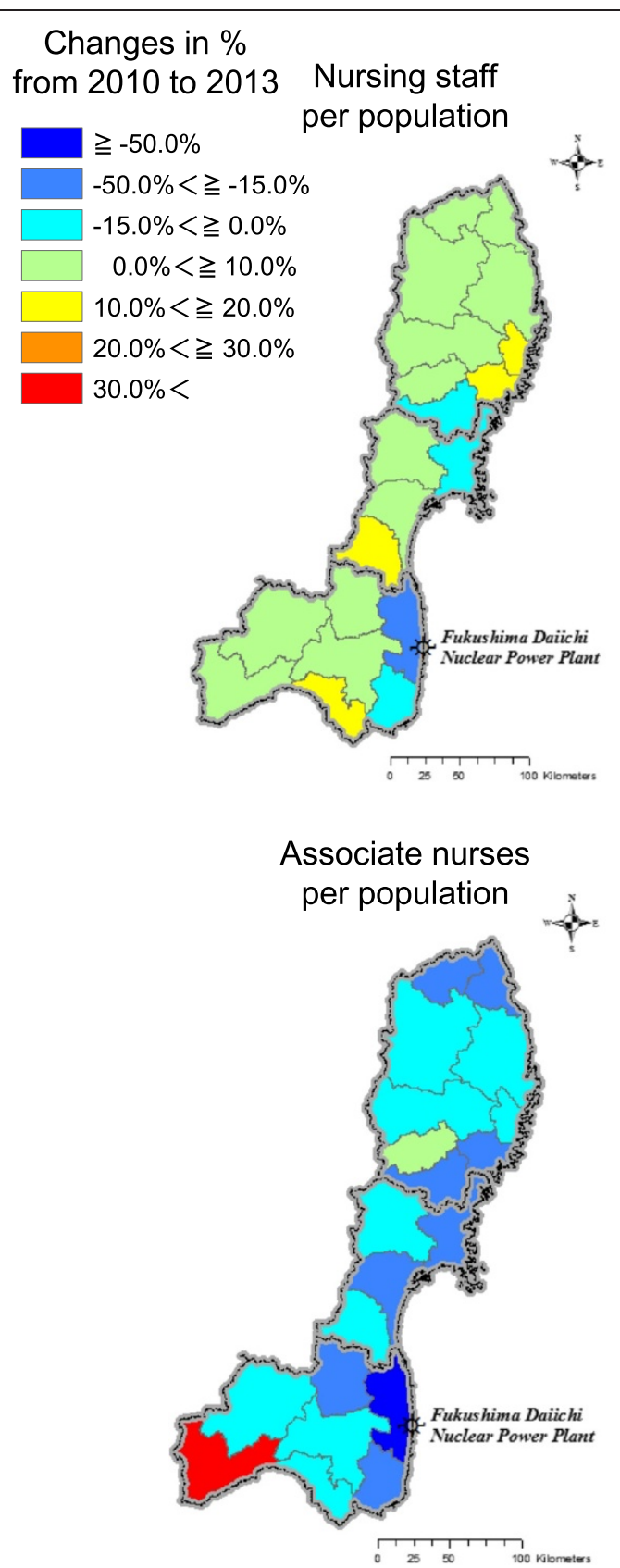
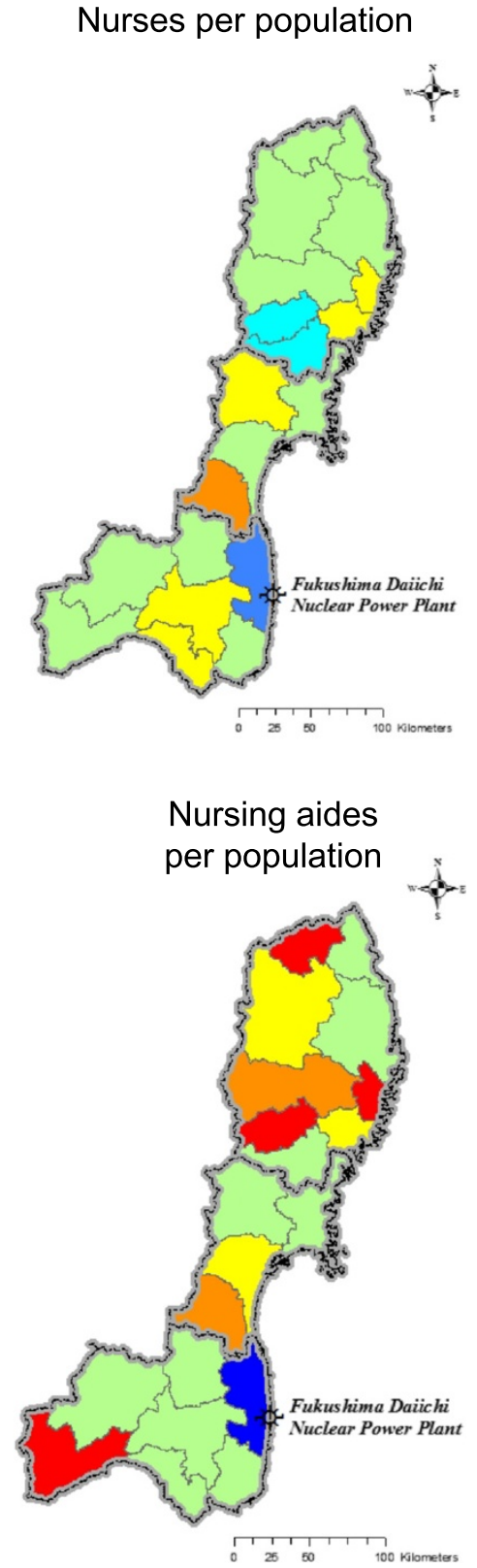

Figure 3 Changes in the ratio of nursing staff per population by qualification from 2010 to 2013.

per population. These large and continuous decreases of nursing staffs might be explained by the following reasons. First, the decrease in the number of hospitals might cause a decrease in the ratio of total nursing staff per population. After the GEJE, the Japanese government designated three categories of areas to which evacuation orders were issued to prevent further expansion of the damage caused by the NPP accident: Area 1, where it is confirmed that the annual cumulative dose will definitely be $\leq 20 \mathrm{mSv}$, is an area in which evacuation orders have already been lifted; Area 2 , where the annual cumulative dose from the present moment is expected to be $>20 \mathrm{mSv}$ and where residents are ordered to remain evacuated in order to reduce the risk of radiation exposure; and Area 3, where the annual cumulative dose is expected be $\geq 20 \mathrm{mSv}$ for a long time, especially within 5 years, and the current annual cumulative dose is $>50 \mathrm{mSv}$, and where it is expected that residents will face difficulties in returning for a long time [34, 35]. Most parts of Areas 1 and 2 have been included in Sousou SMA, and the hospitals located within the areas have been closed [4]. Health care workers who had worked in those hospitals had to 
move, even if they wanted to work there. Even in the hospitals that maintained their functions, the increased workload among the nursing staff, due to the initial significant reductions in the number of available staff after the GEJE, might encourage further departure of nursing staff [36] and discourage their return, which could result in a continuous shortage of nursing staff.

Another possible reason is the concern over radiation exposure among the nursing staff, which might have made them move to areas located far from the NPP. As previous studies have indicated, only half of the health care providers were willing to work in areas affected by nuclear disasters $[6,37-40]$. The most frequently cited reason for employees' unwillingness to report for duty during a disaster was fear and concern for the safety of their families and themselves [37]. Although the surrounding SMAs have also suffered from high doses of radiation, the relatively higher radiation doses and the shorter distance from the NPP in Sousou might be a reason for the larger reduction and delayed return of the nursing staff. There might be some other factors that could be associated with the workforce distribution after the disaster. Although such factors would be strongly associated with the mortality or radiation doses in each SMA, further investigations are required to find those factors that are associated with the workforce distribution.

The change in the ratio of nursing staff per population differed according to qualifications, and the change in ratio of nursing aides was the lowest among the three types of nurses. Cone et al. indicated that willingness to work in a disaster area was higher for nurses than for nonclinical staff [39], but our findings indicated different tendencies. Because most nursing aides are irregular employees in Japan, they might be more likely to change their workplace than nurses are. Also, there might be differences in knowledge regarding radiation. Lanzonni et al. showed that physicians and nurses with knowledge regarding biological events had greater willingness to work in a biological disaster [40].

From the above findings, policy and actions to secure the different types of nursing staff are required, especially for the areas suffering from a continuous shortage of staff. The Fukushima prefectural government developed a policy for securing nurses after the GEJE: (1) establish a study fund aimed at the security of nurses and associate nurses, (2) support re-employment of latent nurses, (3) set aside a subsidy to assist with part of the personnel expenses in the hospitals forced to reduce operation by the GEJE to maintain employment of nurses and (4) strengthen the inservice training in the hospitals within Sousou $[7,15]$. These policies might be partly effective and contribute to the relatively higher ratios of nurses and associate nurses per population than nursing aides, even in Sousou SMA.
To secure the overall nursing staff, however, more comprehensive approaches to enhance the return of nursing aides as well as nurses and associate nurses to the hospitals are required. As the skill mix of nursing staff has been promoted globally [41], a financial incentive was introduced to promote employment of nursing aides in hospitals, which was expected to reduce nurses' workload and allow them to spend more time doing their own professional jobs such as bedside care [42]. According to a previous study, the motivation of nursing aides in Japan can be defined by the following factors: salary satisfaction, free time to do one's own thing, nursing aides as important partners in the job, feeling helpful to patients, participating in decision-making and jobskill improvement [43]. Thus, policies including salary increase, strengthening in-service training and ensuring a pleasant working environment, might be effective in securing nursing aides in Sousou and, consequently, in providing a better work environment by reducing the overall workload of the nursing staff in each hospital. To prevent further reductions in staff and for future preparedness, education programmes regarding nuclear disasters could be effective, since such programmes were found to minimize health care providers' fears and concerns about radiation [44].

In Minamiaizu, not only the ratio of total nursing staff per population but also the ratio of hospitals and physicians per population has been the lowest and much lower than the nationwide levels [45]. The relative shortage and misdistribution of health care providers in remote areas such as Minamiaizu has been a continuous policy concern in Japan [46-48].

To the best of our knowledge, the longitudinal impact of a disaster on the distribution of health care providers is unknown, especially during a nuclear accident. Therefore, this study is the first to show the longitudinal trend in the ratio of total nursing staff per population in SMAs according to qualifications before and after the GEJE.

There were some limitations to our study. First, the population might have been overestimated in those SMAs that were greatly damaged by the GEJE because of evacuation, without people changing area registration. Accordingly, the ratio of total nursing staff per population might have been underestimated in these areas. The Japanese government reported that there are about 133 309 people actually living around restricted areas and areas for which evacuation orders have been issued, such as in the Sousou SMA, excluding three municipalities (Shinchi Town, Soma City and Hirono Town), as of 31 December 2013 [35]. In our study, the population in the same area was 131705 as of 1 October 2013. In considering these numbers, a perceived limitation of overestimation is not serious because the government's calculation of Sousou's population was almost the same as our estimation. Second, there were data limitations with regard to type of 
occupation, workplace and time. In our data, the data before 2007 and other health providers' information did not exist. Trends in other health care providers, such as physicians, dentists and pharmacists, should be clarified in future studies. Total nursing staff included only hospital workers because of data availability. Trends in total nursing staff in other workplaces, such as clinics or long-term care facilities, should be investigated in the future. Third, our findings could not indicate the causal association between the numbers of total nursing staff and effects of radiation because we described the temporal trends using statistical data and did not assess the dynamic flows of nursing staff according to radiation dose. Therefore, further studies are required to investigate the causal association.

\section{Conclusions}

We investigated the temporal trend in the total nursing staff per population before and after the GEJE. Our study indicated that the trend in total nursing staff per population ratio after the GEJE was different between the physically damaged areas and those affected by radiation. Nursing qualifications also showed differences in trends: the reduction in the ratio of total nursing staff per population was larger in Sousou - the area most affected by radiation than in any other SMAs, and that of nursing aides was the largest compared with those of nurses and associate nurses. To promote the reconstruction of the medical care systems after the GEJE, policies for both nurses and nursing aides, considering the influences of radiation, might be required.

\section{Abbreviations}

FTE: Full-time equivalent; GEJE: Great East Japan Earthquake; NPP: Nuclear power plant; SMA: Secondary medical area.

\section{Competing interests}

The authors declare that they have no competing interests.

\section{Authors' contributions}

NM designed the study, collected data, carried out the statistical analyses and drafted and revised the manuscript. JT carried out the statistical analysis and reviewed and revised the manuscript. TS carried out the geographical representation. YK supervised the study design and statistical analyses and reviewed and revised the manuscript. All authors read and approved the final manuscript.

\section{Acknowledgements \\ This study was granted by the Leading Graduates Schools Program "Global Leader Program for Social Design and Management (GSDM)" a Grant-in-Aid for Scientific Research (No. 21119006) by the Ministry of Education, Culture, Sports, Science and Technology, Japan.}

\section{Author details}

'Department of Public Health, Graduate School of Medicine, The University of Tokyo, 7-3-1 Hongo, Bunkyo-ku, Tokyo 113-0033, Japan. ${ }^{2}$ Center for Spatial Information Science, The University of Tokyo, 4-6-1 Komaba, Meguro-ku, Tokyo 153-8505, Japan.

Received: 1 January 2015 Accepted: 10 August 2015

Published online: 25 August 2015

\section{References}

1. Cabinet Office, Government of Japan: White paper on disaster management 2013. 2013. http://www.bousai.go.jp/kaigirep/hakusho/ pdf/H25_honbun_1-4bu.pdf. Accessed 1 Sept 2014.

2. Miura N, Yasuhara K, Kawagoe S, Yokoki H, Kazama S. Damage from the Great East Japan Earthquake and Tsunami - a quick report. Mitig Adapt Strateg Glob Chang. 2011;16:803-18.

3. Ochi S, Nakagawa A, Lewis J, Hodgson S, Murray V. The Great East Japan earthquake disaster: distribution of hospital damage in Miyagi Prefecture. Prehosp Disaster Med. 2014;29:245-53.

4. Tominaga T, Hachiya M, Tatsuzaki H, Akashi M. The accident at the Fukushima Daiichi Nuclear Power Plant in 2011. Health Phys. 2014;106:630-7.

5. Matsumoto M, Inoue K. Earthquake, tsunami, radiation leak, and crisis in rural health in Japan. Rural Remote Health. 2011;11:1759.

6. Chaffee M. Willingness of health care personnel to work in a disaster: an integrative review of the literature. Disaster Med Public Health Prep. 2009;3:42-56.

7. Ministry of Health and Welfare, Fukushima prefectural government: Fukushima Prefecture total nursing staff supply and demand planning 2013. 2013. https://www.pref.fukushima.lg.jp/sec/21045d/ kansenkangokango07.html. Accessed 9 Sept, 2014. (in Japanese)

8. Aiken LH, Sloane DM, Bruyneel L, Van den Heede K, Griffiths P, Busse R, et al. Nurse staffing and education and hospital mortality in nine European countries: a retrospective observational study. Lancet. 2014. doi:10.1016/ S0140-6736(13)62631-8.

9. World Health Organization (WHO): Nursing midwifery services strategic directions 2011-2015. (2010). http://www.who.int/hrh/resources/nmsd/en/. Accessed 22 April 2015.

10. World Health Organization (WHO): The 2014 update, Global Health Workforce Statistics. http://apps.who.int/gho/data/node.main.A1444?lang=en. Accessed 20 April 2015.

11. Izutsu M, Suzuki E, Izutsu Y, Doi H. Trends in geographic distribution of total nursing staff in Japan from 2000 to 2010: a multilevel analysis. Acta Med Okayama. 2014;68:101-10.

12. Medical Care Act, 1948. Article 30-4. http://www.japaneselawtranslation.go.jp/ law/detail/?id=2199\&vm=04\&re=01. Accessed 1 May 2014.

13. Ministry of Health and Welfare, Iwate prefectural government: Iwate Prefecture regional health care plan 2013-2017. 2013. http://www.pref.iwate.jp/iryou/ seido/keikaku/002229.html. Accessed 1 May 2014. (in Japanese)

14. Medical Maintenance Division, Miyagi prefectural government: sixth Miyagi Prefecture community medical program 2013-2017. 2013. http/// www.pref.miyagi.jp/soshiki/iryou/rmpindex.html. Accessed 1 May 2014. (in Japanese)

15. Regional Medical Division, Fukushima prefectural government: sixth Fukushima Prefecture medical plan 2013-2017. 2013. https://www.pref.fukushima.lg.jp/ sec/21045c/iryou-keikaku6.html. Accessed 1 May 2014. (in Japanese)

16. Act on Public Health Nurses, Midwives, and Nurses, 1948. Article 5-12. http://www.japaneselawtranslation.go.jp/law/detail/?id=2075\&vm=04\&re=01. Accessed 1 May 2014.

17. Japanese Nursing Association: Overview of Japanese nursing system. http://www.nurse.or.jp/jna/english/nursing/system.html\#nurses. Accessed 7 Dec 2014.

18. Affairs Department Disaster Prevention Office, Iwate prefectural government: list human casualties and building damage situation of the Tohoku region Pacific Ocean Earthquake (March 31st, 2014). http:// www2.pref.iwate.jp/ bousai/taioujoukyou/201403311700jinntekihigai.pdf. Accessed 14 Apr 2014. (in Japanese)

19. Crisis measures division, Miyagi prefectural government: damage such as the situation in the Great East Japan Earthquake (Feb 28th, 2014). http:// www.pref.miyagi.jp/uploaded/attachment/247174.pdf. Accessed 10 Apr 2014.

20. Disaster Management Division, Fukushima prefectural government. 2011 damage situation immediately report by the Tohoku region Pacific Ocean earthquake ver. 1160 (April 4th, 2014). Fukushima: Fukushima prefectural government; 2014 (in Japanese).

21. Iwate prefectural government. Estimate population by municipalities. Morioka: Iwate prefectural government; 2013.

22. Miyagi prefectural government. Estimate population by municipalities. Sendai: Miyagi prefectural government; 2013.

23. Fukushima prefectural government. Estimate population by municipalities. Fukushima: Fukushima prefectural government; 2013.

24. Garber M, Unger L, White J, Wohlford L: Hurricane Katrina's effects on industry employment and wages. http://www.bls.gov/opub/mlr/2006/08/ art3full.pdf. Accessed 1 August 2015. 
25. United Nations: UNISDR Terminology on Disaster Rsk Reduction. http:// www.unisdr.org/files/7817_UNISDRTerminologyEnglish.pdf. Accessed 3 August 2015.

26. Forestry Agency, Japanese Government: http://www.rinya.maff.go.jp/j/ routai/anzen/pdf/kijun.pdf. Accessed 2 March 2015. (in Japanese)

27. Ministry of the Environment, Japanese Government: Decontamination Guidelines. http://josen.env.go.jp/en/framework/pdf/ decontamination_guidelines_2nd.pdf. Accessed 19 August 2015. http:// www.meti.go.jp/english/press/2011/0826_03.html. Accessed 2 March 2015.

28. Extension Site of the Distribution Map for Radiation Dose. http:// ramap.jmc.or.jp/map/eng/. Accessed 2 March 2015.

29. Tohoku Regional Bureau of Health and Welfare: about the annual reports. http://kouseikyoku.mhlw.go.jp/tohoku/shinsei/shido_kansa/ shisetsu_kijun_teirei/index.html. Accessed 15 Oct 2013. (in Japanese)

30. Hospital report. http://www.mhlw.go.jp/toukei/list/80-1.html. Accessed 10 July 2014.

31. Population estimate. http://www.stat.go.jp/english/data/jinsui/index.htm. Accessed 10 July 2014.

32. National Land Numerical Information download service. http://nlftp.mlit.go.jp/ksj-e/ index.html. Accessed 11 May 2014.

33. Regional Medical Support Center, Fukushima prefectural government: current status of Fukushima Prefecture of medical. https://www.pref.fukushima.lg.jp/sed/ 21045g/iryougenjyou.html. Accessed 11 Nov 2014.

34. Ministry of Economy, Trade, and Industry, Japanese Government: For accelerating the reconstruction of Fukushima from the nuclear disaster -major points-Cabinet Decision on December 20, 2013. http://www.meti.go.jp/ english/earthquake/nuclear/roadmap/pdf/20140605_01.pdf. Accessed 1 May 2015.

35. Areas to which evacuation orders have been issued (December, 2013). http://www.meti.go.jp/earthquake/nuclear/pdf/131231a.pdf. Accessed 10 Oct 2014. (in Japanese)

36. Sato Y, Hayashida N, Orita M, Urata H, Shinkawa T, Fukushima Y, et al. Factors associated with nurses' intention to leave their jobs after the Fukushima Daiichi Nuclear Power Plant accident. PLoS One. 2015. doi:10.1371/journal.pone.0122389.

37. Qureshi K, Gershon RR, Sherman MF, Straub T, Gebbie E, McCollum M, et al. Health care workers' ability and willingness to report to duty during catastrophic disasters. J Urban Health. 2005;82:378-88.

38. Barnett DJ, Thompson CB, Errett NA, Semon NL, Anderson MK, Ferrell JL, et al. Determinants of emergency response willingness in the local public health workforce by jurisdictional and scenario patterns: a cross-sectional survey. BMC Public Health. 2012;12:164.

39. Cone DC, Cummings BA. Hospital disaster staffing: if you call, will they come? Am J Disaster Med. 2006;1:28-36.

40. Lanzilotti SS, Galanis D, Leoni N, Craig B. Hawaii medical professionals assessment. Hawaii Med J. 2002;61:162-73.

41. Buchan J, Dal Poz MR: Skill mix in the health care workforce: reviewing the evidence. Bull World Health Organ. 2002; doi:S0042-96862002000700010.

42. Ministry of Health, Labour and Welfare, Japanese government: FY 2008 Revision of Medical Fee [Heisei 22 nendo sinryouhousyu kaitei]. http:// www.mhlw.go.jp/stf/seisakunitsuite/bunya/kenkou_iryou/iryouhoken/ iryouhoken12/index.html. Accessed 29 April 2015.

43. Kudo Y, Kido S, Shahzad MT, Yoshimura E, Shibuya A, Aizawa Y: Work motivation for Japanese nursing assistants in small- to medium-sized hospitals. Tohoku J Exp Med. 2011; JST.JSTAGE/tjem/225.293.

44. Van Dyke ME, McCormick LC, Bolus NE, 3rd Pevear J, Kazzi ZN. Radiological emergency preparedness: a survey of nuclear medicine technologists in the United States. J Nucl Med Technol. 2013. doi:10.2967/jnmt.113.124677.

45. Regional Medical Division, Fukushima prefectural government: Fukushima Prefecture Regional Medical revitalization plan (Aizu-Minamiaizu medical area). 2009. http://www.pref.fukushima.lg.jp/uploaded/attachment/ 37706.pdf. Accessed 20 Sept 2014. (in Japanese)

46. Kobayashi Y, Takaki H. Geographic distribution of physicians in Japan. Lancet. 1992;340:1391-3.

47. Tanihara S, Kobayashi Y, Une H, Kawachi I. Urbanization and physician maldistribution: a longitudinal study in Japan. BMC Health Serv Res. 2011;11:260.

48. Toyabe S. Trend in geographic distribution of physicians in Japan. Int J Equity Health. 2009;8:5.

\section{Submit your next manuscript to BioMed Central and take full advantage of:}

- Convenient online submission

- Thorough peer review

- No space constraints or color figure charges

- Immediate publication on acceptance

- Inclusion in PubMed, CAS, Scopus and Google Scholar

- Research which is freely available for redistribution

Submit your manuscript at www.biomedcentral.com/submit 